Fayetteville State University

DigitalCommons@Fayetteville State University

$6-2006$

\title{
Sentencing Outcomes Under Competing But Coexisting Sentencing Interventions: Untying The Gordian Knot
}

Miriam A. Delone

Fayetteville State University, mdelone@uncfsu.edu

Paula M. Kautt

University of Cambridge

Follow this and additional works at: https://digitalcommons.uncfsu.edu/crimj_wp

\section{Recommended Citation}

Delone, Miriam A. and Kautt, Paula M., "Sentencing Outcomes Under Competing But Coexisting Sentencing Interventions: Untying The Gordian Knot" (2006). Criminal Justice Faculty Working Papers. 1. https://digitalcommons.uncfsu.edu/crimj_wp/1

This Article is brought to you for free and open access by the Criminal Justice at DigitalCommons@Fayetteville State University. It has been accepted for inclusion in Criminal Justice Faculty Working Papers by an authorized administrator of DigitalCommons@Fayetteville State University. For more information, please contact dballar5@uncfsu.edu. 


\section{Criminal Justice Review \\ http://cjr.sagepub.com/}

\section{Sentencing Outcomes Under Competing But Coexisting Sentencing Interventions: Untying The Gordian Knot \\ Paula M. Kautt and Miriam A. Delone \\ Criminal Justice Review 2006 31: 105 \\ DOI: $10.1177 / 0734016806290138$}

The online version of this article can be found at:

http://cjr.sagepub.com/content/31/2/105

Additional services and information for Criminal Justice Review can be found at:

Email Alerts: http://cjr.sagepub.com/cgi/alerts

Subscriptions: http://cjr.sagepub.com/subscriptions

Reprints: http://www.sagepub.com/journalsReprints.nav

Permissions: http://www.sagepub.com/journalsPermissions.nav

Citations: http://cjr.sagepub.com/content/31/2/105.refs.html 


\author{
Paula M. Kautt \\ Institute of Criminology, University of Cambridge \\ Miriam A. Delone \\ University of Nebraska Lincoln
}

\begin{abstract}
The latest evolutionary phase of criminal sentencing is a return to determinate sentencing structures. However, the concurrent application of sentencing guidelines and mandatory minimum statutes in various jurisdictions often distorts and convolutes evaluations of such interventions' effectiveness. To remedy this problem, the effects of such distinct reforms must be separated from one another. Previous research has been unsuccessful in accomplishing this task. The authors attempt to remedy this deficiency by using 1997-1998 federal sentencing data to isolate the effects of the minima from those of the guidelines and assessing how the predictors and conditioners of sentencing outcomes vary between them. The authors find several significant and some unexpected differences in the effect of predictors across models of incarceration and sentence length for the two intervention types.
\end{abstract}

Keywords: sentencing; sentencing guidelines; mandatory minimum statutes; determinate sentencing; federal courts; judicial decision making; drug offenses

$\mathrm{W}$

hen Alexander the Great came to the city of Gordium, he encountered an unusual puzzle in the form of a wagon bound to a tree by an intricate knot. Oracle prophecy dictated that whomsoever could loose the wagon from this Gordian knot was destined to rule all of Asia. However, despite years of attempts, the riddle had yet to be solved. Alexander, wanting very much to be the foretold conqueror, faced a dilemma.

Unraveling current determinate sentencing outcomes is a modern, albeit less grandiose, parallel to Alexander's predicament. In the United States today, many court systems (both state and federal) concurrently operate under two distinct determinate sentencing strategiessentencing guidelines and mandatory minimum statutes (Bureau of Justice Assistance [BJA], 1998). This coexistence can confound evaluations of sentencing outcomes because the effects of one initiative are not separated from those of the other, making it difficult to discern the impact of either individual intervention. Although many states currently employ both interventions (e.g. Pennsylvania, Minnesota, Ohio, Washington), this problem is particularly salient to the federal system, which, until quite recently, ${ }^{1}$ operated under stringent and presumptive variations of these two strategies.

Although determinate sentencing is not a new idea, this modern reality of coexisting - and in some instances competing-determinate sentencing strategies is a relatively recent 
development. Yet, unlike the Gordian knot of legend, few have attempted to solve the puzzle posed by such coapplication. In fact, much of the research in this area is either unable to separate the influence of such externally imposed interventions (General Accounting Office, 1992) or, more commonly, focuses on the effects of one while ignoring the other (Pasko, 2002; Steffensmeier \& Demuth, 2000; Ulmer \& Johnson, 2004). Although this latter neglect is understandable for offense areas where there is minimal strategy overlap, for offense types where there is often substantial overlap (such as drug offenses), such disregard limits and biases our understanding of determinate sentencing outcomes. Simply, without disaggregating the effects of coexisting determinate sentencing strategies, it is impossible to determine either how the impact of one intervention affects sentencing outcomes or the operation of the other intervention (and vice versa). Yet empirical evaluations have not to date determined whether one structure negates the other's effects or, if in fact, the interventions enhance one another's capacity to achieve the goals for which they were intended. Clearly, it is crucial that researchers disentangle the dynamic of coexisting interventions before assessing whether such sentencing reforms can be termed either successes or failures. Only after this knot is unraveled and the independent effects of such interventions identified can the impact of determinate sentencing reforms be fully understood in both practical and theoretical terms.

The current research seeks to accomplish this task by examining the federal system, arguably the most high profile coupling of structured sentencing interventions. Given the wide use and prevalence of drug-related mandatory minimum statutes at the federal level, we use drug offense data ${ }^{2}$ from fiscal year 1997-1998 to isolate and separate the predictors of sentencing outcomes under the coexisting federal sentencing guidelines (hereafter Guidelines) and federal mandatory minimum statutes (hereafter Minima). ${ }^{3}$ We argue that the threads of "perceptual shorthand" (outlined under perspectives such as focal concerns and causal attribution) and the applicable structured sentencing interventions (e.g., guidelines or mandatory minima) together bind criminal sentencing outcomes, constituting a virtual Gordian knot of sentencing.

\section{Determinate Sentencing Strategies}

Recent years have seen a wide proliferation of determinate sentencing strategies, the most common of which have been sentencing guidelines and mandatory minima (BJA, 1998). Although these strategies are often used in tandem, they are in fact based on distinct and, some argue, competing sentencing rationales. Although several rationales have been used to justify them, sentencing guidelines were primarily undertaken, to reduce the extralegal disparity present under previous indeterminate strategies by standardizing sanctions (Tonry, 1996). Extralegal disparity is present when case attributes not considered legally relevant to the case (e.g., defendant race, marital status, or employment) significantly affect the outcome, even after legally relevant factors are adequately controlled (Johnson, 2005; Mitchell \& MacKenzie, 2005). ${ }^{4}$ Although sentencing guidelines can either be advisory or presumptive (Doob, 1995) and the rationales behind them vary, most U.S. permutations rely on a grid of offense seriousness and criminal history axes (often supplemented by a wide array of departure and adjustment criteria) to direct judges to the appropriate sentence 
for any given crime. Today, several states and the federal government employ sentencing guidelines (Rottman, Flango, Cantrell, Hansen, \& LaFountain, 2000).

At the same time, every state and the federal system have implemented some permutation of mandatory minimum sentencing (Parent, Dunworth, McDonald, \& Rhodes, 1997). Although disparity reduction can be a mandatory minima goal, this objective is generally secondary to the primary goals of "just desserts," deterrence, and incapacitation (Caulkins, Rydell, Scwhabe, \& Chiesa, 1997). Like presumptive sentencing guidelines, mandatory minima require judges to impose a precise, predetermined sentence for particularly specified offenses. However, the composition and operation of the numerous existing mandatory minima varies substantially — both from one another and between systems. For example, some mandatory minima are offense based, specifying a fixed mandatory sentence or sentence enhancement for particular crimes (e.g., violent, weapon, or drug offenses). Others, such as "three strikes" laws, are offender based and mandate particular sentences for offenders with specified prior records - often repeat, violent, or felony offenses (Shichor, 1997). Regardless, mandatory minima purportedly rely solely on one or two case characteristics to demonstrate the seriousness of specific criminal acts. In the federal system, drug offenses are the most prominent minima (Tonry, 1996).

Because of these differences in design and purpose, one would intuitively expect guidelines and mandatory minima to have distinct effects on sentencing outcomes-particularly extralegal sentence disparity. Because guidelines were intended and designed to produce equitable sentences, one would anticipate extralegal factors to have less impact over sentencing outcomes for such cases as compared to others. Conversely, because mandatory minima are primarily used to demonstrate the seriousness of certain crimes, there is no reason to expect them to reduce extralegal sentence disparity. Rather, one might anticipate an increase in such disparity given the demographic distributions of certain targeted offenses (Tonry, 1995).

Given the greater discretion-limiting nature of mandatory minima as compared to guidelines, this argument may seem counterintuitive. One might expect the greater availability of discretionary mechanisms under guidelines to result in greater disparity because, as has been traditionally argued, increased discretion enables increased disparity (Walker, 1993). However, in the case of many state and the federal systems, most drug-related mandatory minima were constructed in a way that emphasizes particular types of offenses-particularly those traditionally perpetrated by certain demographic classes (e.g., crack cocaine). This reality suggests that such extralegal factors may actually have greater impact under mandatory minima cases than guideline cases. In fact, for Black and White drug defendants, this proposition is borne out by recent federal sentencing research (Kautt \& Spohn, 2002).

Likewise, studies of sentencing outcomes under each intervention type support these expectations. Early evaluations of state sentencing guidelines indicate that they significantly reduce extralegal sentencing disparity as compared to the previous systems (Kramer, Lubitz, \& Kempinen, 1989; Miethe \& Moore, 1985; Moore \& Miethe, 1986), although later research reveals that this initial success declined as time passed (Stolzenberg \& D'Alessio, 1994) and that extralegal factors retain significant direct, indirect, and interactive influences over sentencing outcomes (Engen, Gainey, Crutchfield, \& Weis, 2003; Kautt, 2002; Kautt \& Spohn, 2002; Kramer \& Ulmer, 2002; Nicholson-Crotty, 2004; Steffensmeier \& Demuth, 
2001; Steffensmeier, Ulmer, \& Kramer, 1998; Ulmer, 1997; Ulmer \& Johnson, 2004; Ulmer $\&$ Kramer, 1998). On the other hand, mandatory minima research suggests that they increase rather than decrease extralegal disparity (Crawford, 2000; Crawford, Chiricos, \& Kleck, 1998) and have little impact on the targeted crimes (Kovandzic, 2001; Stolzenberg \& D’Alessio, 1997; Worrall, 2004).

Although the effects of sentencing guidelines and various state-level mandatory minima have been evaluated, scant attention is paid to the effect of these two interventions when they are used concurrently (Kautt \& Spohn, 2002; Rodriguez, 2003). Theoretically speaking, because of the different intents and purposes behind each intervention, it is reasonable to expect that their impacts on sentencing outcomes-and the degree to which other predictors affect those outcomes - might be vastly different. Thus, when two such interventions coincide within one sentencing system, one might expect the impact of one to distort the effects of the other, resulting in misleading patterns and erroneous conclusions as to the impact of either. As a result, the coexistence of the two sentencing strategies arguably undermines and contaminates evaluations of each (Vincent \& Hofer, 1994). To our knowledge, only one study has examined this issue in any depth.

Kautt and Spohn (2002) examined the issue of whether offender race, drug type, and sentencing intervention interacted to affect sentencing outcomes. Their analyses demonstrated that the type of sentencing intervention (the minima and guidelines together versus the minima or guidelines alone) conditioned the effect that other case level factors had on the final sentencing outcome. As mentioned previously, the current study uses these earlier findings in conjunction with new analyses to examine federal sentencing outcomes for drug offenses under the hereafter Guidelines and Minima to determine whether the coexistence of two structured sentencing interventions has implications for the interpretation of sentencing outcomes within such systems.

\section{Theoretical Framework}

The two structured sentencing interventions we examine are the product of distinct purposes and expectations concerning their effects on sentencing outcomes. Guidelines are primarily formulated, not out of varied rationales for punishment, but rather the principles of equal protection and due process to produce equitable treatment. As a result, guidelines apply uniformly to all criminal offenses within a given category. Mandatory minima, conversely, are triggered by specific offense circumstances or offender criminal histories. When they are invoked, the penalties are high in accordance with the concepts of (a) specific and general deterrence, (b) incapacitation of chronic offenders ${ }^{5}$ or those who engage in crimes considered particularly egregious, ${ }^{6}$ and (c) retribution for the costs that perpetration of such crimes have inflicted on society (USSC, 1991). Yet despite these distinctions, theorizing about the impact of each sentencing strategy generally does not take these fundamental differences into consideration. Instead, explanations of sentencing outcomes are often independent of both the influence of legislative intent and the specific rationale(s) for punishment proposed.

To illustrate with our federal example, the intent behind and existence of Guidelines and Minima are arguably at odds. The primary Guidelines' goal of reducing disparity is based 
in procedural expectations concerning due process and equal protection. However, Minima are firmly entrenched in traditional rationales for sentencing: deterrence, incapacitation, and retribution. Clearly, these differences should be inextricably tied to the outcomes generated under each intervention. With this in mind, our first hypothesis is as follows:

Hypothesis 1: The structural sentencing strategy under which a case falls (Minima or Guidelines) will significantly affect ${ }^{7}$ the predictors of both incarceration and sentence length.

However, the question remains as to how the differences between the two strategies will affect sentencing outcomes. Taking previous arguments into account, we have derived two conflicting explanations. The first is based on the level of discretion permitted under each structural requisite. Under the Sentencing Reform Act, the USSC developed the Guidelines to incorporate a wide variety of legally relevant factors considered important under prior federal sentencing (Doob, 1995; General Accounting Office, 1992), address specific problems commonly encountered in structured sentencing (such as charge disparity), and allow judicial consideration of individual factors such as family ties or community involvement as justification for sentence mitigation (USSC, 1991). Conversely, Congress itself created and enacted the Minima (USSC, 1997) with the express intent of demonstrating the heinousness of particular offenses (Parent et al., 1997) but without the benefit of expert input afforded the USSC. Because of these differences in design and origin, the Guidelines permit consideration of a wide range of aggravating and mitigating factors, whereas the Minima purportedly rely solely on offense characteristics. Thus, Guideline sentencing involves multiple decision points and looser control over discretion than does sentencing under the Minima. Given that greater discretion can lead to more opportunities for consideration of extralegal factors, one might expect greater sentence disparity under the Guidelines than under the Minima. Simply, the mechanical, discretionlimiting nature of the Minima should curb decision makers' use of causal attribution, whereas the Guidelines would enable these same factors to affect sentencing outcomes. As a result, we might expect larger extralegal disparity under the Guidelines than the Minima.

Our second explanation, however, posits a more complicated dynamic. The variation in both the primary intent behind and means of formulating the Minima and the Guidelines suggests that individual assessments of what constitutes "egregious" entered into Minima but not Guideline construction. Congressional record supports this supposition, showing that causal attribution and "perceptual shorthand" played key roles in determining which offenses and drug types garnered Minima penalties (Tonry, 1995). Thus, it is plausible to surmise the same influences continue to affect courtroom decisions and sentencing outcomes where the Minima are involved. Given this, one might intuitively expect that the influence of causal attribution factors would be greater for Minima than Guideline drug offenses. In other words, officials' beliefs about the relative dangerousness of certain demographic classes of offenders would interact with the "egregious" nature of Minima offenses to enhance and exacerbate any extralegal disparity present under the Guidelines. We believe this latter explanation better captures the true dynamics of federal sentencing under the Guidelines and the Minima. 
Beyond these specific predictions concerning the individual impact of each intervention, it is also important to derive expectations about their combined impact, particularly in the area of drug crime. The unique properties of these offenses exemplify how the strategies' coexistence distorts our understanding of their effects on sentencing outcomes (Schulhofer, 1992). First, drugs are the primary area in which the existing Minima directly shaped the Guideline sentence ranges. This is because the USSC built the Guideline penalty ranges for drug offenses around the existing Minima, making them the rule rather than the exception. Second, the Minima for drug crimes (and therefore the Guideline ranges) are both type and quantity based-often making those the only factors considered-thereby short circuiting the Guidelines' disparity reduction avenues and resulting in different cases being treated alike solely on the basis of drug type and amount. Third, as exemplified by its "relevant conduct" and "substantial assistance" 10 provisions, the Guidelines shifted power and discretion in the courtroom largely from the judge to the prosecutor (Wilmot \& Spohn, 2004), augmenting an already vast realm of unfettered discretion. Fourth, the Guidelines' "relevant conduct" standard treats federal drug offenses uniquely because, by definition, drug distribution is a conspiratorial crime. As a result, when used in concert with the Minima, extreme sentences can be imposed on even the lowest level of players (e.g., "mules" or low level dealers) along with higher level offenders (e.g., suppliers-see Note 9 for further elaboration). Finally, there are substantially more upward adjustment provisions available in the Guidelines than downward adjustments. This is argued to interact with the presence of the Minima to yield large upward sentencing enhancements for drug offenders with little or no comparable potential for downward adjustments (Schulhofer, 1992). These circumstances suggest that the coexistence of the Minima and Guidelines serves to undermine rather than compliment the goals of each.

The key to determining precisely how these interventions will affect sentencing outcomes lies in addressing the mechanisms, triggers, and strategies that each structural intervention uses to achieve its underlying goal. For example, the Guidelines focus primarily on offender prior record and the offense seriousness score ${ }^{11}$ to determine sentence. The operation is simple - the higher these scores, the more severe the sanction. This promotes uniformity as persons who have committed equally serious offenses or possess comparable criminal histories should receive commensurate sentences. Thus, our second and third hypotheses are as follows:

Hypothesis 2: Offense seriousness will have greater positive impact over the odds of incarceration and sentence length for Guideline than for Minima cases.

Hypothesis 3: Defendant criminal history will have greater positive impact over the odds of incarceration and sentence length for Guideline than for Minima cases.

Beyond these, however, additional circumstantial factors come into play in the forms of departure and adjustment mechanisms. These discretionary outlets enable the sentencing judge to mitigate or aggravate the sentences of offenders based on circumstantial differences. Thus, they further promote equity by permitting persons with similar criminal history and offense seriousness scores but differences in culpability and criminal intent to be treated differently. However, these same mechanisms also provide an opportunity for extralegal disparity, as each represents an opportunity to exercise discretion, suggesting that 
departure and adjustment mechanisms are the Guideline avenues through which extralegal sentence disparity can occur.

Conversely, these same factors should have lesser importance under the Minima because neither the criminal history nor final offense seriousness scores are relevant to reaching a final sentencing decision under that intervention. Rather, sanction determination focuses almost exclusively on the offense itself. In the case of drug offenses, legally relevant, causal attribution factors such as drug type, drug amount, and offense type would be the most salient to the final sentencing outcome because they comprise the pertinent offense characteristics under the Minima. As a result, one would expect these factors to wield greater impact on Minima cases as compared to Guideline cases. Their importance under Minima provides one avenue through which extralegal factors could influence the sentencing outcome, leading to additional hypotheses:

Hypothesis 4: Drug type will have greater aggravating effects over the odds of incarceration and sentence length for Minima than for Guideline cases.

Hypothesis 5: Drug amount will have greater aggravating effects over the odds of incarceration and sentence length for Minima than for Guideline cases.

Hypothesis 6: Drug offense type will have greater aggravating effects over the odds of incarceration and sentence length for Minima than for Guideline cases.

This discussion of the hypothesized differences in predictor effects between the two interventions naturally brings us to the theoretical and practical consequences of structural requisite overlap in the federal system. For example, Minima presence effectively blocks the mitigating Guideline departures, such as acceptance of responsibility or having a minor role in the criminal event. Thus, one would intuitively expect that, for cases involving Minima, defendants different in terms of criminal intent or role would be treated similarly. In other words, they would produce unwarranted parity. Likewise, the use of sentence adjustments should vary between the Guidelines and the Minima simply as a function of the different avenues available for each. These realities further illustrate the importance of grouping cases by the structural requisites involved in their disposition.

With such differences in intent, mechanisms, and scope identified, we can derive other specific expectations concerning the influence of legal and extralegal factors under each intervention. Table 1 provides a partial listing of these expectations for the variables used in our analyses. For example, the Guideline relevant factors, such as offense seriousness and criminal history, would have less impact on sentencing outcomes for Minima cases because these factors are not emphasized under that structural intervention. Likewise, Minima criteria, such as specific drug type and amount or offense type, would have reduced impact under Guideline sentencing because the impact of these factors is diluted in the aggregate measure of the final offense seriousness score. Thus, traditionally salient factors would have different effects under the two interventions by virtue of the different attributes emphasized under each. In addition, extralegal factors such as defendant race, ethnicity, or gender would have greater influence on the sentencing outcome under the Minima than the Guidelines by virtue of the different rationales behind the two interventions. This leads to our final hypothesis:

Hypothesis 7: Extralegal offender attributes will have greater effect on sentencing outcomes under the Minima than under the Guidelines. 
Table 1:

Expected Variable Effect and Differences in Effect Between Models

\begin{tabular}{|c|c|c|c|}
\hline & Expected Effect & $\begin{array}{l}\text { Expected Difference } \\
\text { in Effect }\end{array}$ & Rationale \\
\hline \multicolumn{4}{|l|}{ Legal } \\
\hline $\begin{array}{l}\text { Final offense } \\
\text { seriousness } \\
\text { score }\end{array}$ & $\begin{array}{l}\text { Incarceration odds, sentence } \\
\text { length increase with score }\end{array}$ & $\begin{array}{l}\text { Greater aggravating effect } \\
\text { for Guidelines }\end{array}$ & $\begin{array}{l}\text { Greater formal emphasis of } \\
\text { this factor under } \\
\text { Guidelines }\end{array}$ \\
\hline $\begin{array}{l}\text { Criminal history } \\
\text { category }\end{array}$ & $\begin{array}{l}\text { Incarceration odds, sentence } \\
\text { length increase with score }\end{array}$ & $\begin{array}{l}\text { Greater aggravating effect } \\
\text { for Guidelines }\end{array}$ & $\begin{array}{l}\text { Greater formal emphasis of } \\
\text { this factor under } \\
\text { Guidelines }\end{array}$ \\
\hline Crack or meth & $\begin{array}{l}\text { Presence increases imprisonment } \\
\text { odds, sentence length }\end{array}$ & $\begin{array}{l}\text { Greater aggravating effect } \\
\text { for Minima }\end{array}$ & $\begin{array}{l}\text { Minima specify high penalty } \\
\text { ranges for these drugs; } \\
\text { less downward departure } \\
\text { potential }\end{array}$ \\
\hline Marijuana & $\begin{array}{l}\text { Presence decreases odds of } \\
\text { imprisonment and sentence } \\
\text { length compared to cocaine }\end{array}$ & $\begin{array}{l}\text { Greater mitigating effect } \\
\text { for Guidelines }\end{array}$ & $\begin{array}{l}\text { Low Minima penalty ranges } \\
\text { means downward departure } \\
\text { potential }\end{array}$ \\
\hline $\begin{array}{l}\text { Cocaine, crack, or } \\
\text { meth grams }\end{array}$ & $\begin{array}{l}\text { Greater amount has higher } \\
\text { imprisonment odds and } \\
\text { sentence length }\end{array}$ & $\begin{array}{l}\text { Greater aggravating effect } \\
\text { for Minima }\end{array}$ & $\begin{array}{l}\text { These drug amounts are } \\
\text { specifically tied to } \\
\text { Minima penalties }\end{array}$ \\
\hline $\begin{array}{l}\text { Distribution or } \\
\text { manufacture }\end{array}$ & $\begin{array}{l}\text { Increased imprisonment odds } \\
\text { and sentence length over } \\
\text { import/export }\end{array}$ & $\begin{array}{l}\text { Greater aggravating effect } \\
\text { for Minima }\end{array}$ & $\begin{array}{l}\text { Here, Minima specify high } \\
\text { punishment ranges and } \\
\text { have less downward } \\
\text { departure potential }\end{array}$ \\
\hline Possession & $\begin{array}{l}\text { Decreased imprisonment odds } \\
\text { and sentence length over } \\
\text { import/export }\end{array}$ & $\begin{array}{l}\text { Greater mitigating effect } \\
\text { for Guidelines }\end{array}$ & $\begin{array}{l}\text { Minima apply only with } \\
\text { relatively large amounts, } \\
\text { greater Guidelines } \\
\text { downward departure } \\
\text { potential }\end{array}$ \\
\hline \multicolumn{4}{|l|}{ Extralegal } \\
\hline Gender & $\begin{array}{l}\text { Females have lower incarceration } \\
\text { odds and sentence length }\end{array}$ & $\begin{array}{l}\text { Greater mitigating effect } \\
\text { for Guidelines }\end{array}$ & $\begin{array}{l}\text { Chivalry and paternalism } \\
\text { theses interact with } \\
\text { Guidelines departure } \\
\text { opportunities }\end{array}$ \\
\hline Age & $\begin{array}{l}\text { Greater age has higher } \\
\text { imprisonment odds and } \\
\text { sentence length }\end{array}$ & $\begin{array}{l}\text { Greater aggravating effect } \\
\text { for Guidelines }\end{array}$ & $\begin{array}{l}\text { Youth benefit interacts with } \\
\text { increased departure } \\
\text { opportunity of Guidelines }\end{array}$ \\
\hline $\begin{array}{l}\text { Number of } \\
\text { dependents }\end{array}$ & $\begin{array}{l}\text { More dependents gives lower } \\
\text { incarceration odds and } \\
\text { sentence length }\end{array}$ & $\begin{array}{l}\text { Greater mitigating effect } \\
\text { for Guidelines }\end{array}$ & $\begin{array}{l}\text { Familial chivalry will interact } \\
\text { with increased departure } \\
\text { opportunity }\end{array}$ \\
\hline U.S. citizen & $\begin{array}{l}\text { U.S. citizens have higher } \\
\text { incarceration odds but shorter } \\
\text { sentence length }\end{array}$ & $\begin{array}{l}\text { Greater aggravating effect } \\
\text { for Minima, mitigating } \\
\text { Guidelines }\end{array}$ & $\begin{array}{l}\text { Noncitizens more likely to } \\
\text { be deported than } \\
\text { imprisoned under } \\
\text { Guidelines }\end{array}$ \\
\hline $\begin{array}{l}\text { Defendant race- } \\
\text { Black }\end{array}$ & $\begin{array}{l}\text { Blacks have higher incarceration } \\
\text { odds, sentence length }\end{array}$ & $\begin{array}{l}\text { Greater aggravating effect } \\
\text { for Minima }\end{array}$ & $\begin{array}{l}\text { Villain/victim thesis and } \\
\text { representation in targeted } \\
\text { offenses }\end{array}$ \\
\hline $\begin{array}{l}\text { Defendant } \\
\text { ethnicity- } \\
\text { Hispanic }\end{array}$ & $\begin{array}{l}\text { Hispanics have higher } \\
\text { incarceration odds and } \\
\text { sentence length }\end{array}$ & $\begin{array}{l}\text { Greater aggravating effect } \\
\text { for Minima }\end{array}$ & $\begin{array}{l}\text { Villain/victim thesis and } \\
\text { representation in targeted } \\
\text { offenses }\end{array}$ \\
\hline Education level & $\begin{array}{l}\text { Greater level has lower odds of } \\
\text { incarceration and sentence } \\
\text { length }\end{array}$ & $\begin{array}{l}\text { Greater mitigating effect } \\
\text { for Guidelines }\end{array}$ & $\begin{array}{l}\text { Higher education will } \\
\text { interact with increased } \\
\text { departure opportunity }\end{array}$ \\
\hline
\end{tabular}




\section{Method and Analysis}

\section{Strategy}

In alignment with our above expectations, we separate the simple Guideline cases from those eligible for Minima sentencing into two distinct data sets to assess variation in sentencing outcomes for federal drug offenses. In fact, such a partitioning approach is the only analytical strategy that will test our propositions concerning the differential Minima and Guidelines effects on both sentencing outcomes and sentencing predictors. To this end, our research uses a permutation of Kautt and Spohn's (2002) analytical strategy on a drug offense subset of 1997-1998 USSC federal sentencing data subdivided only by sentencing strategy rather than race and sentencing strategy.

To isolate the federal cases involving Minima from those that do not, we used the first and second statutes referenced in the first count of conviction combined with the indicator of minimum sentence length for a drug offense to identify (a) the statutes involved and (b) the drug cases that did or did not have a minimum sentence. With this information, we then created two separate data files - one for cases involving a Minima statute and having a minimum sentence and a second for simple Guideline cases. ${ }^{12}$ This data partitioning enables us to investigate the specific hypotheses outlined above.

\section{Variables and Analyses}

Table 2 provides the frequencies or means of the variables included in the current analyses. We use two dependent variables: incarceration and sentence length. Incarceration is modeled as a simple in (was sentenced to prison) or out (was not sentenced to prison) dichotomy, whereas sentence length is continuous and operationalized as imposed length of incarceration in months ${ }^{13}$ for the main title offense.

Although the indicators we use to represent our theoretical concepts are those traditionally selected for sentencing research, some additional discussion of their specific content is in order. As previously mentioned, we include several elements of Guideline scoring additional to the final offense seriousness and offender criminal history scores. ${ }^{14}$ This decision raises the issue of collinearity, as some of the factors included are incorporated into the final offense seriousness score. Correlation matrices show minimal overlap between the final offense seriousness score and any one of the independent factors. In addition, neither the Variance Inflation Factor nor the Condition Index tests reveal collinearity among these (or any other) variables.

In addition to legally relevant attributes, we control for several extralegal factors, based on theoretical arguments from prior research. First, our offender causal attributes include gender (Daly \& Tonry, 1997), race (Hawkins, 1987), ethnicity (Mirande, 1987), and age (Steffensmeier et al., 1998). Likewise, number of dependents (Daly, 1987), U.S. citizenship, and education level are included based on assumptions that each might mitigate sentence severity. Finally, organizational and environmental context variables are included. We control mode of disposition, seen here as an organizational factor, in accordance with the "jury tax" thesis (Uhlman \& Walker, 1980). Circuit" ${ }^{15}$ is included as a potential environmental influence on sentences. Finally, sample selection bias is a common sentencingdata problem (Zatz \& Hagan, 1985). Thus, we include the hazard rate (Dubin \& Rivers, 
Table 2:

Variable Means and Frequencies

\begin{tabular}{|c|c|c|}
\hline & $\begin{array}{l}\text { Mandatory Minimum } \\
\text { Drug Offenses }\end{array}$ & $\begin{array}{c}\text { Guideline Drug } \\
\text { Offenses }\end{array}$ \\
\hline \multicolumn{3}{|l|}{ Incarcerated? } \\
\hline Yes & 12,385 & 6,692 \\
\hline No & 310 & 1,144 \\
\hline Length of sentence in months & 103.80 & 33.34 \\
\hline \multicolumn{3}{|l|}{ Drug type dummies } \\
\hline Crack & 3,906 & 925 \\
\hline Powder cocaine $^{a}$ & 3,470 & 1,268 \\
\hline Heroin & 1,174 & 633 \\
\hline Marijuana & 2,167 & 3,888 \\
\hline Methanmphetamine & 1,749 & 401 \\
\hline Other drugs & 242 & 362 \\
\hline \multicolumn{3}{|l|}{ Drug amount in grams } \\
\hline Cocaine & 164.41 & 59.50 \\
\hline Crack & 74.68 & 8.62 \\
\hline Heroin & 42.42 & 24.39 \\
\hline Methanmphetamine & 66.88 & 9.44 \\
\hline Marijuana & 247.91 & 93.62 \\
\hline Other drug & 17.77 & 49.14 \\
\hline \multicolumn{3}{|l|}{ Offense code dummies } \\
\hline Distribution & 84 & 6 \\
\hline Import/export $^{\mathrm{a}}$ & 838 & 1,812 \\
\hline Communication facility & 2 & 400 \\
\hline Possession & 29 & 569 \\
\hline Manufacture & 11,779 & 4,925 \\
\hline \multicolumn{3}{|l|}{ Final criminal history category } \\
\hline 1 & 6,598 & 4,602 \\
\hline 2 & 1,559 & 869 \\
\hline 3 & 1,862 & 973 \\
\hline 4 & 849 & 389 \\
\hline 5 & 360 & 189 \\
\hline 6 & 981 & 479 \\
\hline \multicolumn{3}{|l|}{ Presence of criminal history } \\
\hline Yes & 9,551 & 5,041 \\
\hline $\mathrm{No}^{\mathrm{a}}$ & 3,169 & 2,472 \\
\hline Statutory minimum sentence in months & 101.70 & 7.62 \\
\hline Number conviction counts & 1.49 & 1.29 \\
\hline \multicolumn{3}{|l|}{ Downward departure } \\
\hline Yes & 1,019 & 1,531 \\
\hline $\mathrm{No}^{\mathrm{a}}$ & 11,386 & 6,079 \\
\hline \multicolumn{3}{|l|}{ Substantial assistance departure } \\
\hline Yes & 4,483 & 2,142 \\
\hline $\mathrm{No}^{\mathrm{a}}$ & 7,922 & 5,468 \\
\hline
\end{tabular}


Table 2 (continued)

\begin{tabular}{|c|c|c|}
\hline & $\begin{array}{l}\text { Mandatory Minimum } \\
\text { Drug Offenses }\end{array}$ & $\begin{array}{c}\text { Guideline Drug } \\
\text { Offenses }\end{array}$ \\
\hline \multicolumn{3}{|l|}{ Safety valve departure } \\
\hline Yes & 4,148 & 619 \\
\hline $\mathrm{No}^{\mathrm{a}}$ & 8,628 & 7,274 \\
\hline \multicolumn{3}{|l|}{ Career criminal status } \\
\hline Yes & 631 & 262 \\
\hline $\mathrm{No}^{\mathrm{a}}$ & 12,086 & 7,249 \\
\hline Final offense seriousness score & 28.11 & 17.36 \\
\hline \multicolumn{3}{|l|}{ Gender } \\
\hline Female & 1,408 & 1,353 \\
\hline Male $^{\mathrm{a}}$ & 11,368 & 6,536 \\
\hline Age & 32.91 & 32.41 \\
\hline Number of dependents & 1.70 & 1.51 \\
\hline \multicolumn{3}{|l|}{ U.S. citizen } \\
\hline Yes & 8,980 & 5,096 \\
\hline $\mathrm{No}^{\mathrm{a}}$ & 3,796 & 2,797 \\
\hline \multicolumn{3}{|l|}{ Defendant race } \\
\hline Black & 5,154 & 1,836 \\
\hline White $^{\mathrm{a}}$ & 6,923 & 5,501 \\
\hline \multicolumn{3}{|l|}{ Defendant ethnicity } \\
\hline Hispanic & 4,908 & 4,054 \\
\hline Non-Hispanic ${ }^{a}$ & 7,860 & 3,766 \\
\hline Education level & 10.48 & 10.33 \\
\hline \multicolumn{3}{|l|}{ Trial } \\
\hline Yes & 1,294 & 301 \\
\hline $\mathrm{No}^{\mathrm{a}}$ & 11,455 & 7,563 \\
\hline \multicolumn{3}{|l|}{ Circuit dummies } \\
\hline 1st circuit & 385 & 198 \\
\hline 2nd circuit & 909 & 757 \\
\hline 3rd circuit & 654 & 221 \\
\hline 4th circuit & 1,857 & 630 \\
\hline 5th circuit & 2,032 & 2,077 \\
\hline 6th circuita & 1,016 & 508 \\
\hline 7th circuit & 585 & 189 \\
\hline 8th circuit & 939 & 315 \\
\hline 9th circuit & 1,734 & 1,893 \\
\hline 10th circuit & 601 & 417 \\
\hline 11th circuit & 2,225 & 637 \\
\hline DC circuit & 109 & 51 \\
\hline$N$ & 12,776 & 7,893 \\
\hline$N$ valid & 9,519 & 5,754 \\
\hline
\end{tabular}

a. Reference category. 
1989/1990) to control for any selection bias present. We expect that all included factors will have significant direct effects. However, the impact of many characteristics is expected to change by specific sentencing strategy. Thus, we address potential interactions between the specific sentencing intervention and the other independent variables with our partitioning strategy. ${ }^{16}$

Although Tobit has been used to concurrently estimate the incarceration and sentence length decisions (Albonetti, 1997), we consider this approach inappropriate because the two decisions are made consecutively rather than concurrently (Spohn, Gruhl, \& Welch, 1981-1982; Steffensmeier \& Demuth, 2000). In addition, we expect some independent variables to influence incarceration and sentence length in separate and distinct ways, a possibility precluded when Tobit is used to simultaneously model both decisions. Therefore, we model the dependent variables separately by using logistical regression (Logit) to estimate incarceration and ordinary least squares regression to model sentence duration. Finally, to compare the coefficients of one model to another, we calculate and report the $z$ test for the equality of coefficients (Clogg, Petkova, \& Haritou, 1995). ${ }^{17}$ To test our hypotheses regarding the proposed differences in effect for groups of factors on the incarceration and sentence length decisions, we also conduct the Wald Test for structural change $\mathrm{e}^{18}$ and the Chow test, respectively (Greene, 2000). In addition, as a preliminary step, we conducted a simple $t$ test for difference of means for sentence length, which indicated significant differences in sentence length between the two types of cases. ${ }^{19}$

\section{Results}

Table 3 presents the logistic regression coefficients (and standard errors) analyzing our first dependent variable (incarceration) for the Minima and Guideline case subsamples. The final column in the table represents the results from the $z$ test for equality of coefficients (Clogg et al., 1995). Both the Wald and the Chow test results for the models indicate a significant difference in the cumulative predictor effects between the Minima and Guideline models. Comparisons, using these same tests, of the cumulative effects of the extralegal defendant factors revealed similar results. At the same time, however, it is important to note that there are minor differences in the control variables used for each subsample because of the offense behaviors unique to each group of cases. ${ }^{20}$

\section{Incarceration}

The Minima analysis results indicate that a number of legal case features are significant predictors of the decision to incarcerate. The findings indicate that only offenders convicted of a marijuana offense had significantly lower imprisonment odds than those convicted of a powder cocaine offense. Notably, the impact of crack cocaine offenses was not a significant predictor of incarceration. No drug amount variables emerge as significant predictors of incarceration. However, higher final offense seriousness scores significantly increase the likelihood of incarceration. Offender prior record, represented by the criminal history category, predictably had a positive effect on incarceration odds. Additionally, the legal (but idiosyncratic) decisions of downward departure and substantial assistance departure had the impact of significantly decreasing odds of incarceration. 
Table 3

Strategy Specific Logit Estimations of the Determinants of Incarceration and $z$ Test

\begin{tabular}{|c|c|c|c|c|c|}
\hline \multirow[b]{2}{*}{ Variable } & \multicolumn{2}{|c|}{ Mandatory Minimum } & \multicolumn{2}{|c|}{ Guidelines } & \multirow[b]{2}{*}{$z$} \\
\hline & $b$ & $S E$ & $b$ & $S E$ & \\
\hline Crack cocaine & 0.282 & 0.283 & -0.041 & 258 & \\
\hline Heroin & 0.397 & 0.402 & -0.442 & 286 & \\
\hline Marijuana & $-0.591 *$ & 0.250 & 0.128 & .190 & $-2.286^{*}$ \\
\hline Methamnphetamine & 0.233 & 0.332 & -0.353 & .319 & \\
\hline Other drugs & -0.317 & 0.506 & -0.339 & .291 & \\
\hline Powder cocaine amount & -0.000 & 0.000 & 0.000 & .000 & \\
\hline Crack amount & 0.000 & 0.000 & $-0.0005^{*}$ & .000 & \\
\hline Heroin amount & -0.000 & 0.000 & 0.000 & .000 & \\
\hline Methamnphetamine amount & 0.000 & 0.000 & 0.000 & .001 & \\
\hline Other drug amount & 0.000 & 0.000 & 0.000 & .000 & \\
\hline Marijuana amount & -0.000 & 0.000 & 0.000 & .000 & \\
\hline Distribution & -0.542 & 0.801 & - & - & \\
\hline Communication facility & - & - & $-1.835 * *$ & .316 & \\
\hline Possession & - & - & $-1.9623 * *$ & .308 & \\
\hline Manufacture & -0.628 & 0.356 & $-0.4784 * *$ & .173 & \\
\hline Final criminal history category & $0.455^{* *}$ & 0.106 & $0.6729 * *$ & .068 & $-1.714 *$ \\
\hline Presence of criminal history & -0.090 & 0.192 & 0.138 & .141 & \\
\hline Career criminal status & -0.366 & 0.381 & $-0.6358 * *$ & 223 & \\
\hline Final offense seriousness score & $0.108^{* *}$ & 0.020 & $0.3186 * *$ & .019 & $-7.566 * *$ \\
\hline Number conviction counts & 0.068 & 0.099 & 0.111 & .145 & \\
\hline Gender & $-1.294 * *$ & 0.182 & $-0.6881 * *$ & .135 & $-2.669 * *$ \\
\hline Age & $-0.018^{*}$ & 0.007 & $-0.0149 *$ & .006 & \\
\hline Number of dependents & 0.043 & 0.054 & 0.043 & .039 & \\
\hline U.S. citizen & $-1.303 * *$ & 0.306 & $-2.1533 *$ & .224 & $2.236^{*}$ \\
\hline Black & 0.019 & 0.069 & -0.085 & .050 & \\
\hline Hispanic & 0.276 & 0.238 & 0.238 & .159 & \\
\hline Education level & $-0.120 * *$ & 0.036 & $-0.0919 * *$ & .026 & \\
\hline Downward departure & $-3.253 * *$ & 0.572 & $-1.8996 * *$ & .204 & $-2.228^{*}$ \\
\hline Substantial assistance departure & $-4.209 * *$ & 0.518 & $-2.9238 * *$ & .171 & $-2.354 * *$ \\
\hline Safety valve departure & -0.083 & 0.206 & -0.349 & 276 & \\
\hline PO statutory minimum sentence & -0.001 & 0.002 & -0.004 & .004 & \\
\hline Trial & 1.502 & 1.286 & 0.357 & .565 & \\
\hline 1 st circuit & -1.076 & 0.569 & 0.426 & .492 & \\
\hline 2nd circuit & $-2.390 * *$ & 0.438 & $-1.1442 * *$ & .312 & $-2.315 * *$ \\
\hline 3rd circuit & $-1.693 * *$ & 0.451 & $-1.0447 * *$ & .377 & \\
\hline 4th circuit & $-1.673 * *$ & 0.448 & 0.439 & .322 & $-3.827 * *$ \\
\hline 5 th circuit & -0.139 & 0.462 & 0.132 & .263 & \\
\hline 7th circuit & -0.102 & 0.703 & 0.074 & .519 & \\
\hline 8th circuit & $-1.291 * *$ & 0.463 & -0.416 & .323 & \\
\hline 9th circuit & -0.689 & 0.433 & 0.153 & .279 & \\
\hline 10th circuit & $-1.549 * *$ & 0.480 & -0.559 & .332 & $-1.696^{*}$ \\
\hline 11th circuit & -0.551 & 0.440 & 0.294 & .312 & \\
\hline DC circuit & $-3.357 * *$ & 0.549 & $-1.9258 * *$ & .620 & $-1.726^{*}$ \\
\hline Constant & 8.477 & 0.999 & 1.510 & .573 & \\
\hline$-2 \log$ likelihood/model $X^{2}$ & $1,216.689$ & 730.951 & $1,924.980$ & $1,790.804$ & \\
\hline$R_{L}^{2} / \Phi_{\mathrm{p}}$ & .375 & .133 & .481 & .556 & \\
\hline Number of cases/df & 9,498 & 41 & 5,705 & 42 & \\
\hline
\end{tabular}

NOTE: $\mathrm{PO}=$ probation officer.

$* p<.05 . * * p<.01$. 
A number of extralegal defendant and circuit characteristics also emerged to impact odds of incarceration. Although race and ethnicity had no impact on odds of incarceration, gender and age measures revealed that females and older offenders exhibited significantly lower incarceration odds than comparable males and younger offenders. Defendant's U.S. citizenship and higher education level also worked to mediate the odds of incarceration. Finally, the likelihood of incarceration for similar defendants was not found to be consistent across federal judicial circuits; those sentenced in the second, third, fourth, eighth, 10th, and DC circuits had significantly lower incarceration odds than those sentenced in the sixth circuit.

Guideline cases demonstrate an intriguing pattern of differences and similarities to Minima cases. Surprisingly, crack cocaine amount has an inverse effect on imprisonment odds, thus lowering the odds of incarceration. Although not relevant for Minima cases, the three offense types (possession, use of communication facility, and manufacture) are less likely to result in imprisonment than the more serious drug import/export. Focusing on key Guideline features (final criminal history category, final offense seriousness score, and presence of either a downward or a substantial assistance departure), we find essentially the same significant effects on the likelihood of incarceration as we found for the Minima model. Yet unlike the previous models, the legal issue of the application of career criminal status to the offender emerges as a factor that decreases imprisonment odds. As for extralegal concerns, being female, older, and a U.S. citizen and having a higher level of education decreased the odds of incarceration, as we saw with the Minima cases. Finally, circuitspecific findings again indicate that the odds of incarceration vary by circuit, with defendants sentenced in the second, third, and DC circuits having lower incarceration odds than those sentenced in the sixth circuit.

Although initial comparison of these two models reflect few differences, we take an additional step to test whether the impact of variables that appear to have a similar relationship are significantly more influential in one model versus the other (via the $z$ tests results presented in the final column of Table 4). Several significant differences are present. For example, the mitigating impact of marijuana was greater for Minima cases, whereas the effect of drug amount (impact of crack cocaine compared to powder) was not significantly different between Minima and Guideline cases. Comparison of offender legal characteristics further revealed that the final criminal history category and offense seriousness score both had greater aggravating impact for Guideline drug offenses than for Minima offenses. However, the legally relevant organizational variables for downward departures and substantial assistance departures revealed a greater impact on decreasing the odds of incarceration for Minima cases than for Guideline cases.

Extralegal variables also reveal contrasts across the models analyzed. Gender has a greater impact for Minima cases than for Guideline cases, whereas the benefit of U.S. citizenship is significantly greater for Guideline cases. Following up on the theme of circuit variation, the $z$ test results confirm that intercircuit variation is significantly different across sentencing strategy, with many circuits reflecting generally lower odds of incarceration than the comparison circuit, with the divergences being more marked for Minima sentencing patterns than for Guideline sentencing. It is also interesting to note that comparison of the $R 2 L$ for these models indicates that the model explains more variation for Guideline drug offenses than for Minima cases. 
Table 4

Sentence Length Estimates-Strategy Specific Drug Offenses

\begin{tabular}{|c|c|c|c|c|c|}
\hline \multirow[b]{2}{*}{ Variable } & \multicolumn{2}{|c|}{ Mandatory Minimum } & \multicolumn{2}{|c|}{ Guideline } & \multirow[b]{2}{*}{$z$} \\
\hline & $b$ & $S E$ & $b$ & $S E$ & \\
\hline Crack cocaine & 0.574 & 2.188 & $3.006^{*}$ & 1.515 & \\
\hline Heroin & 4.149 & 3.089 & -1.167 & 1.854 & \\
\hline Marijuana & $13.411 * *$ & 2.326 & 1.738 & 1.267 & $4.407 * *$ \\
\hline Methamnphetamine & 0.753 & 2.595 & 2.371 & 2.036 & \\
\hline Other drugs & -3.388 & 5.359 & 2.523 & 2.395 & \\
\hline Powder cocaine amount & 0.000 & 0.000 & 0.000 & 0.001 & \\
\hline Crack amount & $0.007 * *$ & 0.001 & -0.003 & 0.001 & $5.77 * *$ \\
\hline Heroin amount & $-0.005^{*}$ & 0.002 & -0.002 & 0.002 & \\
\hline Methamnphetamine amount & 0.000 & 0.001 & 0.003 & 0.002 & \\
\hline Other drug amount & 0.000 & 0.001 & 0.000 & 0.000 & \\
\hline Marijuana amount & 0.000 & 0.000 & 0.000 & 0.000 & \\
\hline Distribution & $33.857 * *$ & 8.864 & - & - & \\
\hline Communication facility & - & - & $-23.332 * *$ & 2.074 & \\
\hline Possession & - & - & $-9.505 * *$ & 2.942 & \\
\hline Manufacture & $-6.460 * *$ & 2.786 & $-2.024^{*}$ & 0.980 & \\
\hline Final criminal history category & $15.662 * *$ & 0.616 & $8.124 * *$ & 0.344 & $10.68 * *$ \\
\hline Presence of criminal history & 0.488 & 1.877 & -0.005 & 0.952 & \\
\hline Career criminal status & $15.866 * *$ & 2.898 & $16.462 * *$ & 1.952 & \\
\hline Final offense seriousness score & $7.707 * *$ & 0.168 & $4.180 * *$ & 0.089 & $18.58 * *$ \\
\hline Number conviction counts & $4.451 * *$ & 0.391 & $7.426^{* *}$ & 0.371 & $-5.51 * *$ \\
\hline Gender & $-10.601 * *$ & 2.324 & $-3.796 * *$ & 1.055 & $-2.66 * *$ \\
\hline Age & $-0.298 * *$ & 0.075 & $-0.131 * *$ & 0.039 & $-1.98^{*}$ \\
\hline Number of dependents & $1.297 * *$ & 0.394 & $0.500^{*}$ & 0.227 & $1.75^{*}$ \\
\hline U.S. citizen & -2.456 & 2.048 & $-4.028 * *$ & 1.122 & \\
\hline Black & -0.343 & 0.474 & -0.119 & 0.310 & \\
\hline Hispanic & -3.078 & 2.008 & -0.888 & 1.074 & \\
\hline Education level & -0.353 & 0.256 & $-0.362 * *$ & 0.135 & $10.07 * *$ \\
\hline Downward departure & $-38.828^{* *}$ & 2.671 & $-15.430^{* *}$ & 1.179 & $-8.01 * *$ \\
\hline Substantial assistance departure & $-72.283 * *$ & 1.728 & $-32.967 * *$ & 1.165 & $-18.86 * *$ \\
\hline Safety valve departure & 3.113 & 1.931 & $-10.939 * *$ & 1.560 & $5.66^{* *}$ \\
\hline PO statutory minimum sentence & $0.539 * *$ & 0.010 & $0.541 * *$ & 0.009 & \\
\hline Trial & $54.014 * *$ & 2.497 & $21.041 * *$ & 2.115 & \\
\hline 1st circuit & $-14.027 * *$ & 4.852 & -4.830 & 2.978 & \\
\hline 2nd circuit & $-24.390 * *$ & 4.068 & -0.486 & 2.282 & $-5.12 * *$ \\
\hline 3rd circuit & $-14.644 * *$ & 4.124 & -4.953 & 2.923 & $-1.91 *$ \\
\hline 4th circuit & -5.022 & 3.466 & $6.462 * *$ & 2.214 & $-2.79 * *$ \\
\hline 5th circuit & -3.036 & 3.101 & 2.706 & 1.850 & \\
\hline 7th circuit & -2.421 & 4.180 & 5.530 & 2.887 & \\
\hline 8th circuit & $-11.010 * *$ & 3.763 & 3.264 & 2.418 & $-3.19 * *$ \\
\hline 9th circuit & $-8.541^{*}$ & 3.369 & 1.598 & 1.957 & $-2.60 * *$ \\
\hline 10th circuit & $-8.904 *$ & 4.046 & -1.296 & 2.288 & \\
\hline 11th circuit & -5.661 & 3.077 & -1.023 & 2.088 & \\
\hline DC circuit & $-51.221 * *$ & 7.940 & $-25.119 * *$ & 4.937 & $-2.79 *$ \\
\hline Hazard rate & $-164.84 * *$ & 14.281 & $-50.115^{* *}$ & 3.342 & $-7.82^{*}$ \\
\hline Constant & -0.484 & 16.081 & -4.743 & 4.292 & \\
\hline$R^{2} /$ adjusted $R^{2}$ & .668 & .667 & .745 & .743 & \\
\hline
\end{tabular}

NOTE: $\mathrm{PO}=$ probation officer.

${ }^{*} p<.05 . * * p<.01$. 


\section{Sentence Length}

Table 4 displays the results of the sentence length models. For Minima offenses, offense type generally reveals no significant differences compared to the excluded category, powder cocaine; marijuana is the exception. Marijuana offenses produce sentences that are significantly longer on average than those resulting from conviction of a powder cocaine offense (13 months). Notably, the presence of crack cocaine had no significant effect on sentence length; however, crack cocaine amount significantly lengthens sentences. Amount of heroin also affected sentence length, shortening the average sentence compared to powder cocaine amounts. Offense behavior also exhibits differential impact on sentence length, with conviction of drug distribution resulting in longer sentences than conviction of drug import/exportation, whereas conviction of drug manufacture produces shorter sentences.

Legally relevant offender characteristics consistently had a significant impact on sentence length. Notably, the final criminal history category, the final offense seriousness score, and the application of career criminal status demonstrated a positive relationship with sentence length. However, various organizational decisions by courtroom actors operated to significantly shorten sentence length compared to defendants who were not assigned such decisions: The presence of a downward or a substantial assistance departure, as well as acceptance of the Pre-Sentence Report recommended sentence, shortened sentence length. It is interesting to note that the presence of a substantial assistance departure-designed to mitigate the impact of minimum sentences - has no demonstrable effect on reducing sentence length. Finally, the decision by the offender to proceed to trial netted a significant increase in sentence length (4.5 years) compared to offenders who compromised with plea agreements.

As for extralegal individual offender attributes, female offenders receive shorter sentences than their male counterparts, whereas defendant age has an inverse relationship with sentence length. Additionally, the number of defendant's dependents had the impact of increasing sentence length, whereas U.S. citizenship had no impact on sentence length. With regard to differences by federal judicial circuit, sentences in the first, second, third, eighth, ninth, 10th, and DC circuits are shorter, on average, than those from the sixth circuit, but none are offering significantly longer sentences.

Examination of the analysis of Guideline offenses demonstrated another pattern. Crack cocaine offenses produce sentences nearly 3 months longer than comparable powder cocaine offenses, even when controlling for relevant sentencing factors. Although no drug amount factors are significant predictors of Guideline sentence length, conviction of drug manufacture, possession, or communication facility offenses results in significantly shorter sentences than drug import/exportation. As expected, the influence of Guideline structural featuresfinal criminal history category and final offense seriousness score are significant factors contributing to sentence length. Indicators similar to criminal history and offense seriousness also contribute to lengthening offender sentences: application of criminal career status and the number of conviction counts. Key organizational (vernacular) decisions, such as the presence of a downward, substantial assistance, or safety valve departure, all significantly related to shorter sentence lengths. Finally, taking a case to trial nets a "jury tax" of more than 21 months.

With regard to extralegal offender characteristics, neither race nor ethnicity has any significantly discernable direct impact on sentence length. However, gender and age do mitigate 
sentences, with female and older defendants receiving significantly shorter sentences than males and younger defendants. Those defendants identified as having a higher educational status or U.S. citizenship decreased sentence length as well. Considering the analysis results from the circuit indicators, sentences from the DC circuit are shorter, on average, than those received in the sixth circuit, whereas those received in the fourth circuit are longer. Finally, the $R^{2}$ for these models indicates that the Guidelines model explains approximately $8 \%$ more of the variance in sentence length than the Minima model.

The $z$ test results are presented in the final column of Table 4 and indicate substantial differences in predictor effects between the two sentencing strategies. The effect of marijuana presence, crack amount, the final criminal history category, the final offense seriousness score, the application of career criminal status, and the presence of a downward or a substantial assistance departure were all marked by a significantly greater impact on sentencing outcomes for Minima than Guideline offenses. However, the impact of the number of conviction counts and the presence of a safety valve departure was greater for Guideline drug offenses than for Minima drug offenses, with other variables showing no real difference in impact (heroin amount, trial, etc). Extralegal offender characteristics of gender, age, and number of dependents had larger effects for Minima than Guideline offenses (U.S. citizenship was not shown to have a true difference between models). Examination of the results for circuits indicates that five circuits do have a significantly larger variation in sentence length than the excluded circuit under the Minima (second, third, eighth, ninth, and DC) than the Guidelines cases, whereas the fourth circuit is the only one to have a significantly larger variation in sentence length than the excluded circuit for Guidelines cases compared to Minima cases.

\section{Discussion and Conclusion}

This research found that different determinate sentencing strategies wield distinct influences on sentencing predictors and outcomes. This result is particularly salient given that numerous systems currently operate under coexisting determinate sentencing strategies. Exploring this vein of research will hopefully provide a more accurate assessment of such interventions' effectiveness net of the influence of any other coexisting strategy. Although the findings of previous research provide strong evidence supporting this approach, until now, there has been a distinct absence of research concerning it, particularly in terms of intervention overlap.

Our current findings bolster our call to integrate distinct determinate sentencing strategies and the rationales behind them into modern sentencing theory. The results strongly support Hypothesis 1, revealing that several predictors of incarceration and sentence length vary significantly by the sentencing strategy under which a case falls (e.g., Minima versus Guidelines). Moreover, both the Wald and Chow test results comparing the effects of the saturated Guideline and Minima models (for incarceration and sentence length, respectively) verify that the cumulative effect of the predictors under the two interventions differs significantly. This evidence suggests that the various structural requisites present within a given sentencing system are indeed salient influences to consider when predicting and explaining sentencing outcomes for that system. 
Our results further provide mixed support for our second and third hypotheses, which posit that the offense seriousness and the defendant criminal history score would have greater positive impact on the odds of incarceration and sentence length for Guideline than for Minima cases. Although these expectations hold true in the incarceration models, they do not in the sentence length models. Although there are significant differences in these variables' effects by structural requisite, the magnitude of those effects is unexpectedly greater in Minima cases than for Guideline cases. To explain this, we revisit the triggers and mechanisms of each intervention to derive a plausible explanation for these counterintuitive findings. This reinvestigation led us to focus on the limited opportunity for nonincarcerative sentences available under Minima. This distinct lack of opportunity for discretion in the incarceration decision suggests that the primary interplay between these two legally relevant factors and the Minima could only occur in the sentence length decision. In other words, for Minima cases, there is de facto no incarceration decision, as most cases require imprisonment. As a result, only the sentence length decision remains as a potential outlet for these legally relevant causal attribution factors to affect sentencing outcomes under Minima.

This recognition enables us to provide a viable explanation for the unexpected change in the effects of final offense seriousness and defendant criminal history between the Minima sentence length and incarceration models. Taking the aforementioned realities into consideration, we believe that the interaction of causal attribution (judicial perceptions of Minima offenders) and structural requisites produces the larger effects of both the offense seriousness score and final criminal history category on sentence length for Minima cases as compared to Guideline cases. Further recalling that the Guidelines always apply to any given Minima case, our unexpected results lead us to suspect that the impact of the offense seriousness and prior record factors under the Guidelines is simply amplified for Minima cases. In other words, the impact of these Guideline factors is augmented by the overlay of the Minima, with the Guideline effects being the baseline to which the effect of the Minima is simply added. This interpretation fits well with the punishment rationale behind the Minima, as both offense seriousness and prior record are indicative of both threat and harm to society. Thus, our findings, which seem counterintuitive at first blush, are readily explained when considered in light of the specific mechanisms and functioning of each intervention.

However, the results presented above provide only weak support for our fourth through sixth hypotheses (that drug type, drug amount, and offense type will each have greater positive effects on incarceration odds and sentence length for Minima than for Guideline cases). For example, although there was only one (marijuana) significant difference in effect for incarceration among these factors, it was only partially in the expected direction, having larger mitigating impact for Minima than Guideline cases. Despite this and although there were few significant differences in magnitude of effect among these predictors for sentence length, Hypotheses 4 and 5 are supported by the fact that both marijuana and amount of crack cocaine exhibited larger aggravating effects for Minima cases than for Guideline cases.

These mixed results lead us to question why so few of these theoretically salient factors wielded direct influence on sentencing outcomes or varied in effect across the structural requisites. As one explanation, the combination of results suggests that the Guideline factors 
(offense seriousness and criminal history) might short circuit the direct impact of the drug and offense indicators. Specifically, the variables representing the offense-based factors might affect sentencing outcomes indirectly, operating through the final offense seriousness score. This possibility would be particularly salient when considered in light of the previously mentioned Guideline outlets for prosecutorial discretion (namely, the relevant conduct and substantial assistance provisions) and how they come into play in terms of the calculation of the offense seriousness score. In fact, an additional battery of modelswithout final offense seriousness included-provides strong support for these suppositions. ${ }^{21}$ The Guideline incarceration model and both sentence length models all indicate significant indirect effects for several of these factors. Yet the Minima incarceration model does not. Taken as a whole, these results indicate that the structural requisites involved and the primary causal attribution factors (offense seriousness and criminal history) emphasized under one intervention condition the impact of other offense-based causal attribution factors-except for in the incarceration decision for Minima. These findings not only accentuate the importance of modeling incarceration and sentence length separately but also affirm our earlier interpretations concerning the lack of effect of offense seriousness under the Minima incarceration model. Moreover, in terms of our hypotheses, we find that although we were correct in expecting a reduced impact of these factors under the Minima for incarceration, our expectations were incorrect concerning sentence length, as a result of our not taking into account the conditioning effect of the Guideline factors on Minima predictors and sentencing outcomes. Thus, we find that the primary legal causal attribution factors often condition the impact of specific offense-related legal causal attribution factors and call for future research to elaborate further on this point.

Moving forward, our findings also provide only mixed evidence in support of our seventh hypothesis, which expected extralegal offender attributes to have greater effect on sentencing outcomes under the Minima than under the Guidelines. Although the Wald and Chow tests indicate significant differences in the cumulative predictor effect of extralegal offender attributes between the two interventions, the effects of the individual factors are not entirely as expected. For example, the incarceration model shows that although defendant gender and age had a mitigating impact on both Minima and Guideline sentencing, gender had a greater mitigating impact under Minima cases, but no difference was apparent for age. Likewise, Minima cases demonstrate a more substantial mediating influence of higher education, whereas the Guidelines cases permit a larger mediating influence of citizenship status. Similar patterns emerged for sentence length. Gender, age, and number of dependents all have a significant impact on sentencing under both interventions, but that impact is significantly more profound in Minima cases. Conversely, education level indicates a greater mitigating effect under Guidelines. Together, these results suggest that the conditioning effect of structural requisites on extralegal factors is not as simple or straightforward as we first imagined.

However, we again find that the individual impact of these factors can be explained in terms of the rationales behind and mechanisms present under each structural intervention. For example, the gender effects uncovered support for our previous argument concerning the influence of causal attribution (in terms of the gender-appropriate roles and perceived recidivism risk for females) under the Minima as compared to Guidelines. Likewise, the only aggravating factor, number of defendant's dependents, has a larger effect for the 
Minima, supporting our earlier suggestion of an amplifying effect of causal attribution-based factors under the Minima compared to Guideline sentencing, as having custody of dependent children while pursuing drug activity is often perceived as particularly heinous. Also of note, the only factors that are of greater influence under the Guidelines (citizenship status and education) are not generally seen as corollaries of the punishment rationale for Minima but rather as important offender characteristics to ensure just, individualized punishments - the goal of Guidelines. Thus, these results confirm the dual influence of individual causal attributions and the rationales behind the structural requisites in conditioning the effects of extralegal, offender characteristics.

Beyond this, findings outside our formally articulated hypotheses proved noteworthy. The safety valve mechanism has no effect on incarceration under any strategy and, more intriguing, shortens sentences for Guideline cases while having no effect on sentence length for Minima cases. This is especially perplexing given that the safety valve was primarily intended to influence Minima sentences (Wray, 1993). One possible explanation for this surprising finding is that use of the safety valve provision simply changes the strategy under which cases fall by turning what would be a Minima case into a Guideline case-particularly for possession offenses-given that there is no minimum requisite sentence to impose. This possibility echoes findings by Kautt and Spohn (2002) and suggests the existence of a third theoretical (rather than formal) category for structural requisites that represents the overlap of the two interventions. This grouping, which Kautt and Spohn term hybrid, would comprise cases where the offense itself is labeled as particularly egregious under Minima but where the structural requisite under which the cases fall is the Guidelines (because of safety valve departures or failure to meet the minimum criteria, such as drug quantity, for invoking the statutorily imposed minimum sentence). Theoretically, outcomes for such cases should be mutually affected by both Guideline and Minima characteristics, thereby constituting a grouping of offense outcomes explained by elements of both sentencing interventions currently examined.

Although additional analyses accounting for this third theoretical grouping support this interpretation, they are unable to conclusively explain the current influence of this factor. Kautt's (2002) multilevel analysis of federal sentencing outcomes suggests that district, judicial, and prosecutorial-level factors wield significant influence on these case-level outcomes. This possibility identifies one limitation of our analyses and demonstrates the need for a multilevel analysis of the effects coexisting sentencing interventions might have on sentencing outcomes.

Moreover, because we use secondary data, we cannot take into account the policies, politics, and practices of the circuit and district courts. Future federal sentencing research should endeavor to incorporate site visits to capture the political climate and culture of the federal sentencing locales. Such features currently escape quantification in existing data sets. Finally, our use of a single year of data precludes control for year-to-year variation. Although a longitudinal design would enable examination of how the impact of structural intervention may have changed over time, particularly during "moral panics" regarding particular drug types, given the yearly inconsistency in USSC federal sentencing data, accounting for the influence of time would require separate analysis of each yearly data set.

Yet despite these shortcomings, our results unequivocally suggest that past conclusions regarding the success or failure of particular structural requisites in the various state or 
federal systems are biased when two or more interventions coexist within the same system but are not controlled. Given recent movements to limit discretion in other areas of the criminal justice system, our findings have global applicability to larger criminal justice issues. This study indicates that coexisting formal structural mechanisms seeking to channel or limit discretion in those courts will necessarily affect one another regardless of venue. When extrapolated to other areas of the justice system, it becomes readily apparent that such coexisting interventions have serious implications for both discretion use and the application of the law. For example, American policing has recently undergone several changes, including a movement toward community involvement and the implementation of mandatory arrest polices for instances of domestic assault. However, the philosophies behind the latter strategy, namely deterrence and incapacitation (Hirschel, Hutchinson, Dean, \& Mills, 1992), are in opposition with those of the former movement-that the police and the public are equal partners in crime prevention (Goldstein, 1987). The in-practice dynamic of such coexisting yet diametrically opposed strategies and tactics may do much to explain the current inconsistency in findings concerning the impact of both interventions. Obviously, a similar dynamic may be occurring between the competing punishment and treatment rationales that pervade American corrections today. Based on these findings, it seems clear that future sentencing researchers would benefit from considering the strategy under which a particular case falls in addition to other theoretical themes currently en vogue.

Our research separated and estimated the effects of the coexisting federal determinate sentencing strategies, finding that the predictors of sentencing outcomes vary in terms of significance and operation for Guideline and Minima cases. This suggests that structural interventions direct and condition the influence of both legal and extralegal factors on sentencing outcomes. The question remains, however, precisely how such effects may manifest in other systems where guidelines and minima coexist. Naturally, hypothesizing about any such system would necessitate a thorough understanding of the mechanisms under that system. For example, in examining the potential effects of the Pennsylvania sentencing guidelines and Pennsylvania mandatory minima on sentencing outcomes in that state, one must first establish if and how the two strategies overlap in the population of cases brought before the Pennsylvania courts. Additionally, the origins and applications of the interventions are also important to consider. For example, did the minima shape the guideline structure in the same way as in the federal system, or are the two perhaps independent of one another, thereby producing cases where one intervention "trumps" another? Answering such questions about a given set of interventions is a key first step to assessing whether the patterns we have uncovered in the federal system hold true for other systems.

We began with a discussion of Alexander the Great's Gordian knot. How did Alexander solve this dilemma? Rather than untying the knot, he simply cut it. Our approach is not as direct, but we have separated the Minima's impact from that of the Guidelines. Although the resulting "prize" is not so glamorous, we believe that it is crucial to fully understanding the impact and implications of the various structured sentencing reforms of the 1980s. This reward will be most salient to future research endeavors aimed at understanding modern determinate sentencing and its outcomes. 


\section{Notes}

1. In early 2005, the U.S. v. Booker decision made the federal sentencing guidelines advisory rather than presumptive.

2. Although some might argue that such analyses should first encompass several offenses, in our view, to expand the focus of the current analyses and encompass multiple offense types would unnecessarily complicate the statistical model, reduce its efficiency, and make a test of our premise (differences in effect by structural intervention) virtually impossible. As previous research has argued (Albonetti, 1998), each different offense type necessitates controls for specific offense characteristics (e.g., degree of injury and victim characteristics for violent offenses, dollar amount involved for property offenses, and some white-collar offenses). Including multiple offense types in one model is, therefore, not parsimonious and would clearly produce model misspecification. Added to this is our concern about using cases that fall under federal mandatory minimum statutesof which the most commonly used are drug offenses-so that we can test our hypotheses. For the analyses to be meaningful, they must focus on an offense type where mandatory minima are frequently but not always used. Drug offenses achieve this better than any other offense type available.

3. Note that minima is the plural form of minimum.

4. Despite general agreement in findings of extralegal sentence disparity, to date, there has been little agreement in their explanation. Although some use a "disproportionate involvement" thesis to account for sentencing differences between various demographic offender groups (Blumstein, 1982; Hindelang, 1978), many studies suggest it results from the amount of discretion permitted in the handling of a case (Bushway \& Piehl, 2001; Klepper, Nagin, \& Tierney, 1983; Parker \& Maggard, 2005). In fact, most recent sentencing research relies on theories based on court actors' perception of defendant characteristics and assessment of risk posed. Such orientations include bounded rationality (Albonetti, 1986, 1991), focal concerns (Steffensmeier et al., 1998), and causal attribution (Bridges \& Steen, 1998).

5. Three strikes laws constitute a prime example of this class of mandatory minima. See 42 Pa. C.S. § 9714, which encompasses violent offences as an example from outside the federal system.

6. These are primarily violent, weapon, and drug offenses. Outside the Federal system, these are exemplified by 18 Pa. C.S. § 1102, 42 Pa. C.S. § 9712, and 18 Pa. C.S. § 2506, respectively.

7. As indicated by previous research (Albonetti, 1997; Kautt \& Spohn, 2002; Steffensmeier et al., 1998), such a proposition of differences in effects across groups or classifications of cases is best tested via a partitioned analysis strategy coupled with the $z$ test for the equality of coefficients. The results of both sets of analyses will indicate whether there is a conditioning effect on the coefficients by the partitioned factor (Clogg et al., 1995; Paternoster, Brame, Mazerolle, \& Piquero, 1998).

8. This refers to the quick assessment of offender and offense characteristics by court actors to make sentencing decision. Theoretical perspectives using perceptual shorthand include bounded rationality (Albonetti, 1986, 1991), focal concerns (Steffensmeier et al., 1998), and causal attribution (Bridges \& Steen, 1998). Under such frameworks, court actors attempt to reduce their uncertainty about offender recidivism by using "perceptual shorthand" for evaluating defendants. This shorthand links racial, ethnic, and gender stereotypes to criminal justice processing decisions, resulting in harsher sentences for certain classes of offenders (Albonetti, 1991). Although most risk-reduction perspectives incorporate varied ranges of factors, such as disparity produced by local court variation (Ulmer, 1997; Ulmer \& Kramer, 1996), perceived degree of harm and blameworthiness (Wheeler, Mann, \& Sarat, 1988), offender characteristic interactions (Steffensmeier et al., 1998), or offense stereotypes (Schlesinger, 2005; Steen, Engen, \& Gainey, 2005), the basic causal mechanism remains the same. Sentences and sentencing disparity are the result of causal attributions designed to predict defendants' future behavior and protect the community served. Thus, young, Black, and male offenders receive harsher sentences than similarly situated White, female, and older defendants (Fearn, 2005; Steffensmeier et al., 1998).

9. This requires judges to sentence defendants for acts suggested by a preponderance of the evidence rather than only for convicted behavior. Originally meant to safeguard offenders with only minor levels of culpability from the Minima and prevent abuse of prosecutorial discretion, it forces judges to consider the totality of the offenders' actions and put unusual crimes, such as embezzlement or mail fraud, into the appropriate context (Tonry, 1996; USSC, 1991), the most important reality is that a defendant can plead guilty to or be found guilty of one charge only to be sentenced for additional acts. Thus, the prosecutor needs only convict on one charge, then revive the others at sentencing. Critics contend that this, disturbingly, has the effect of making convictions 
on any related counts unimportant (Doob, 1995) and potentially creates rather than reduces sentencing disparity (General Accounting Office, 1992). It also has the effect of penalizing acts to which the defendant's guilt could not be proven to the satisfaction of the law and permits exertion of undue prosecutorial pressure on a defendant to plead guilty.

10. Under the Guidelines, the prosecutor also has the discretion of whether to initiate the substantial assistance justification for a downward departure. This refers to the exemption that allows judges to depart from both the Guidelines and the Minima if a defendant supplies "significant assistance" to the investigation or prosecution of another defendant. Additionally, plea bargains have a more overt impact on sentence severity under the Guidelines than they did previously (Doob, 1995). Aside from the aforementioned instances, courtroom workgroups use "hidden plea bargaining" to arrive at what they consider to be a reasonable sentence. One USSC estimate reveals that $17 \%$ of all cases results in "hidden plea" sentence reduction. This percentage increases when only drug cases are examined. There, approximately $27 \%$ of the cases involve some form of "hidden plea bargaining" (USSC, 1991).

11. It is important to note that the final offense seriousness score is an aggregate scale designed to represent several separate offense and offender characteristics such as offense type, amount and type of drugs involved, number of conviction counts, and career criminal status. As a result, the expected impact of each factor in light of the structural requisite's goal must be discerned.

12. The variable capturing the first statute referenced in the first conviction count was recoded into a numeric variable that retained the same information as the original string variables. Next, the indicator for the minimum sentence length for the drug offense was recoded into a dichotomous variable indicating whether there was (1) or was not (0) a drug-related minimum sentence involved. These two new variables were multiplied to create a third variable capturing the statutes involved in cases with a minimum sentence. Frequencies of this new variable provided a listing of the specific statutes involved. Comparison of this list to the USSC list of Minima statutes (which was updated by the first author via a Lexis/Nexis search of federal statutes) enabled identification and isolation of mandatory sentence cases that fell under Minima statutes. Recoding of this third variable into a fourth variable permitted removal of those statutes that are not Minima. This fourth variable was then recoded into a fifth variable, which was a dichotomous indicator of whether the case involved both a minimum sentence and a Minima statute (1) or not (0). This process was repeated for the variable, indicating the second statute referenced in the first conviction count. Once this step was accomplished, the final new variable was summed with a fifth new variable from the first process to yield an indicator of whether both a minimum sentence and Minima were involved in either the first or the second statute referenced. If the end value was one or two, both a minimum sentence and a Minima were involved in the case. If the end value was zero, then neither was involved and the case was classified as a simple Guidelines drug case.

13. Some argue that because of the positively skewed nature of this variable, the correct specification would be semilogged in $Y$. We used the $P e$ test (Greene, 2000) to determine if this is the correct specification. The results were inconclusive, so we defaulted to the linear additive model.

14. Notably, we include several legally relevant indicators of key structural requisites that come from the Guideline statutes and procedures. Although some researchers argue that the inclusion of these legally relevant factors together with the final offense seriousness score results in a "double-counting" of their effects, we believe this assertion is theoretically flawed. It is important to remember that the final offense seriousness score is an aggregate score of several multidimensional and widely varying attributes. Relying solely on that composite to reflect the impact of these factors will greatly oversimplify and misrepresent their actual independent effects. Such a strategy would be akin to taking attributes such as age, gender, race, and education, merging them into a single score and then drawing conclusions about them. It would simply be an unintelligible jumble of attribute information that masks any one factor's independent effects. The same is true of the offense seriousness score and, in the case of federal sentencing outcomes, the presumptive sentence or sentencing midpoint (Engen \& Gainey, 2000). In fact, several factors composing the offense seriousness score (offense type, amount and type of drugs involved, number of conviction counts, and presence of career criminal status) are theoretically important enough to individually control their potential direct effects.

Although this discussion may suggest that the individual attributes, rather than the final offense seriousness score, should be included in any federal sentencing models, this is not a viable option. The nature of Guideline sentencing (final offense level and criminal history categories intended to be the primary sentencing factors) means that exclusion of the final offense seriousness score would produce severe model misspecification. Yet 
disregarding the potential independent effects of the aforementioned factors would also produce misspecification. Thus, we see the parts of the final offense seriousness score as greater than their aggregate whole and include these factors as well as offense seriousness accordingly.

15. Although some use the DC circuit as the reference category, we find this inappropriate. First, it produces comparisons of circuits comprising several states to a circuit that is a city. Second, this circuit produces the least number of cases, thereby distinguishing it from other circuits. Given this, the DC circuit can hardly be described as a "typical" circuit. The sixth circuit was chosen as the reference category partially because of numbers. It is at neither the high or low extreme.

16. In preliminary models, we investigated a parabolic relationship between age and sentence length (Steffensmeier et al., 1998) as well as the possibility that conviction counts and offense level have diminished impact on sentence length (Greene, 2000). The results were inconclusive, dictating that we default to the nonparabolic model.

17. It is important to note that we include as many of the same parameters in both models as is supported by our expectations and the data themselves. The rationale being that in addition to establishing which factors are salient under which intervention, to unnecessarily change the specification across the models will reduce the validity of the $z$ test for equality of coefficients. Specifically, if the functional form varies across the models compared, then the coefficients would be naturally expected to vary as a product of the different functional forms used rather than because of the influence of the different sentencing interventions.

18. See Greene (2000, pp. 292-293) for specification of this procedure.

19. As with many studies using secondary data, information on theoretically influential factors is missing for some cases. Nearly $5 \%$ of the cases have no data on either the final criminal history category or final offense seriousness. Unfortunately, eliminating these variables is not feasible because each was designed to wield significant and substantial influence on Guideline sentencing outcomes. Thus, cases with missing data for them are simply omitted. This reality, however, changes our data from being the population of federal drug cases sentenced in 1997-1998 to merely a biased sample of those cases. As a result, issues that apply to samples also apply to our data.

20. Analysis of Minima cases requires controls for drug manufacture and distribution, whereas Guideline cases require controls for drug possession and manufacture as well as the use of a communication facility in the commission of a drug offense.

21. These results are available from the first author on request.

\section{References}

Albonetti, C. A. (1986). Criminality, prosecutorial screening, and uncertainty: Theory of discretionary decisionmaking in felony. Criminology, 24, 623-644.

Albonetti, C. A. (1991). An integration of theories to explain judicial discretion. Social Problems, 38, 247-266.

Albonetti, C. A. (1997). Sentencing under the federal sentencing guidelines: Effects of defendant characteristics, guilty pleas, and departures on sentence outcomes for drug offenses. Law and Society Review, 31(4), 789-822.

Albonetti, C. A. (1998). The role of gender and departures in the sentencing of defendants convicted of a whitecollar offense under the federal sentencing guidelines. In J. T. Ulmer (Ed.), Sociology of crime, law, and deviance (vol. 1, pp. 3-47). Greenwich, CT: JAI Press.

Blumstein, A. (1982). On the racial disproportionality of United States' prison populations. Journal of Criminal Law and Criminology, 73, 1259-1281.

Bridges, G., \& Steen, S. (1998). Racial disparities in official assessments of juvenile offenders: Attributional stereotypes as mediating mechanisms. American Sociological Review, 63(4), 554-570.

Bureau of Justice Assistance. (1998). 1996 national survey of state sentencing structures (No. 169270). Washington, DC: U.S. Department of Justice/Bureau of Justice Assistance.

Bushway, S. D., \& Piehl, A. M. (2001). Judging judicial discretion: Legal factors and racial discrimination in sentencing. Law \& Society Review, 35(4), 733-764.

Caulkins, J. P., Rydell, C. P., Scwhabe, W. L., \& Chiesa, J. (1997). Mandatory minimum drug sentences: Throwing away the key or taxpayers' money? Santa Monica, CA: RAND. 
Clogg, C. C., Petkova, E., \& Haritou, A. (1995). Statistical methods for comparing regression coefficients between models. American Journal of Sociology, 100, 1261-1293.

Crawford, C. (2000). Gender, race, and habitual offender sentencing in Florida. Criminology, 38(1), $263-279$.

Crawford, C., Chiricos, T., \& Kleck, G. (1998). Race, racial threat, and sentencing of habitual offenders. Criminology, 36(3), 481-512.

Daly, K. (1987). Structure and practice of familial-based justice in a criminal court. Law and Society Review, $21,267-290$.

Daly, K., \& Tonry, M. (1997). Gender, race and sentencing. In M. Tonry (Ed.), Crime and justice: A review of research (vol. 22, pp. 201-252). Chicago: University of Chicago Press.

Doob, A. N. (1995). The United States sentencing commission guidelines: If you don't know where you are going, you might not get there. In C. Clarkson \& R. Morgan (Eds.), The politics of sentencing reform (pp. 199-250). Oxford, UK: Clarendon.

Dubin, J. A., \& Rivers, D. (1989/1990). Selection bias in linar regression, logit and probit models. Sociological Methods and Research, $18(2 \& 3), 360-390$.

Engen, R. L., \& Gainey, R. R. (2000). Modeling the effects of legally relevant and extralegal factors under sentencing guidelines: The rules have changed. Criminology, 38(4), 1207-1230.

Engen, R. L., Gainey, R. R., Crutchfield, R. D., \& Weis, J. G. (2003). Discretion and disparity under sentencing guidelines: The role of departures and structured sentencing alternatives. Criminology, 41(1), 99-130.

Fearn, N. E. (2005). A multilevel analysis of community effects on criminal sentencing. Justice Quarterly, 22(4), 452-487.

General Accounting Office. (1992). Sentencing guidelines: Central questions remain unanswered (No. GAO/GDD 92-93). Washington, DC: General Accounting Office/Government Printing Office.

Goldstein, H. (1987). Toward community oriented policing: Potential, basic requirements and threshold questions. Crime \& Delinquency, 33(1), 6-30.

Greene, W. H. (2000). Econometric analysis (4th ed.). Upper Saddle River, NJ: Prentice Hall.

Hawkins, D. F. (1987). Beyond anomalies: Rethinking the conflict perspective on race and capital punishment. Social Forces, 65(3), 719-743.

Hindelang, M. J. (1978). Race and involvement in common law personal crimes. American Sociological Review, 43, 93-109.

Hirschel, J. D., Hutchinson, I. W., Dean, C. W., \& Mills, A. M. (1992). Review essay on the law enforcement response to spouse abuse: Past, present and future. Justice Quarterly, 9(2), 247-283.

Johnson, B. D. (2005). Contextual disparities in guidelines departures: Courtroom social context, guidelines compliance and extralegal disparities in criminal sentencing. Criminology, 43(3), 761-797.

Kautt, P. (2002). Location, location, location: Interdistrict and intercircuit variation in sentencing outcomes for federal drug-trafficking offenses. Justice Quarterly, 19(4), 633-671.

Kautt, P., \& Spohn, C. (2002). Cracking down on black drug offenders? Testing for interactions between offender race, drug type, and sentencing strategy in federal drug sentences. Justice Quarterly, 19(1), 1-35.

Klepper, S., Nagin, D., \& Tierney, L. (1983). Discrimination in the criminal justice system - A critical appraisal of the literature. In A. Blumstein, J. Cohen, S. E. Martin, \& M. H. Tonry (Eds.), Research on sentencing - The search for reform (pp. 55-128). Washington, DC: National Academies Press.

Kovandzic, T. V. (2001). The impact of Florida's habitual offender law on crime. Criminology, 39(1), $179-204$.

Kramer, J. H., Lubitz, R. L., \& Kempinen, C. A. (1989). Sentencing guidelines: A quantitative comparison of sentencing policies in Minnesota, Washington, and Pennsylvania. Justice Quarterly, 6(4), 565-587.

Kramer, J. H., \& Ulmer, J. T. (2002). Downward departures for serious violent offenders: Local court "corrections" to Pennsylvania's sentencing guidelines. Criminology, 40(4), 897-932.

Miethe, T. D., \& Moore, C. A. (1985). Socioeconomic disparities under determinate sentencing systems: A comparison of preguideline and postguideline practices in Minnesota. Criminology, 23(2), 337-363.

Mirande, A. (1987). Gringo justice. Notre Dame, IN: University of Notre Dame Press.

Mitchell, O., \& MacKenzie, D. L. (2005). Relationship between race, ethnicity, and sentencing outcomes: A meta-analysis of sentencing research. Washington, DC: U.S. Department of Justice, National Institute of Justice.

Moore, C. A., \& Miethe, T. D. (1986). Regulated and unregulated sentencing decisions: An analysis of first year practices under Minnesota's felony sentencing guidelines. Law and Society Review, 20(2), 253-277. 
Nicholson-Crotty, S. (2004). The impact of sentencing guidelines on state-level sanctions: An analysis over time. Crime \& Delinquency, 50(3), 395-411.

Parent, D., Dunworth, T., McDonald, D., \& Rhodes, W. (1997). Key legislative issues in criminal justice: Mandatory sentencing: Research in action. Washington, DC: National Institute of Justice.

Parker, K. F., \& Maggard, S. R. (2005). Structural theories and race-specific drug arrests: What structural factors account for the rise in race-specific drug arrests over time? Crime \& Delinquency, 51(4), 521-547.

Pasko, L. (2002). Villain or victim: Regional variation and ethnic disparity in federal drug offense sentencing. Criminal Justice Policy Review, 13(4), 307-328.

Paternoster, R., Brame, R., Mazerolle, P., \& Piquero, A. (1998). Using the correct statistical test for the equality of regression coefficients. Criminology, 36(4), 859-866.

Rodriguez, N. (2003). Impact of "strikes" in sentencing decisions: Punishment for only some habitual offenders. Criminal Justice Policy Review, 14(1), 106-127.

Rottman, D. B., Flango, C. R., Cantrell, M. T., Hansen, R., \& LaFountain, N. (2000). State court organization, 1998.Washington, DC: Bureau of Justice Statistics.

Schlesinger, T. (2005). Racial and ethnic disparity in pretrial criminal processing. Justice Quarterly, 22(2), 170192.

Schulhofer, S. J. (1992). Assessing the federal sentencing process: The problem is uniformity not disparity. American Criminal Law Review, 28(833), 833-873.

Shichor, D. (1997). Three strikes as public policy: The convergence of the new penology and the Mcdonaldization of punishment. Crime \& Delinquency, 43(4), 470-492.

Spohn, C., Gruhl, J., \& Welch, S. (1981-1982). The effects of race on sentencing: A re-examination of an unsettled question. Law and Society Review, 16(1), 71-88.

Steen, S., Engen, R. L., \& Gainey, R. R. (2005). Images of danger and culpability: Racial stereotyping, case processing and criminal sentencing. Criminology, 43(2), 435-467.

Steffensmeier, D., \& Demuth, S. (2000). Ethnicity and sentencing outcomes in U.S. federal courts: Who is punished more harshly? American Sociological Review, 65(5), 705-729.

Steffensmeier, D., \& Demuth, S. (2001). Ethnicity and judges' sentencing decisions: Hispanic-Black-White comparisons. Criminology, 39(1), 145-178.

Steffensmeier, D., Ulmer, J., \& Kramer, J. (1998). The interaction of race, gender, and age in criminal sentencing: The punishment cost of being young, Black, and male. Criminology, 36(4), 763-798.

Stolzenberg, L., \& D'Alessio, S. J. (1994). Sentencing and unwarranted disparity: An empirical assessment of the long term impact of sentencing guidelines in Minnesota. Criminology, 32(2), 301-310.

Stolzenberg, L., \& D'Alessio, S. J. (1997). Three strike and you're out: The impact of California's new mandatory sentencing law on serious crime rates. Crime \& Delinquency, 43(4), 457-469.

Tonry, M. (1995). Malign neglect. New York: Oxford University Press.

Tonry, M. (1996). Sentencing matters. New York: Oxford University Press.

Uhlman, T. M., \& Walker, N. D. (1980). He takes some of my time; I take some of his: An analysis of judicial sentencing patterns in jury cases. Law and Society Review, 14(2), 323-339.

Ulmer, J. T. (1997). Social worlds of sentencing: Court communities under sentencing guidelines. Albany: State University of New York Press.

Ulmer, J. T., \& Johnson, B. (2004). Sentencing in context: A multilevel analysis. Criminology, 42(1), 137-177.

Ulmer, J. T., \& Kramer, J. H. (1996). Court communities under sentencing guidelines: Dilemmas of formal rationality. Criminology, 34(3), 383-408.

Ulmer, J. T., \& Kramer, J. H. (1998). The use and transformation of formal decision-making criteria: Sentencing guidelines, organizational contexts and case processing strategies. Social Problems, 45(2), 248-267.

U.S. Sentencing Commission. (1991). Special report to congress: Mandatory minimum penalties in the federal criminal justice system. Washington, DC: Author.

U.S. Sentencing Commission. (1997). Special report to congress: Cocaine and federal sentencing policy. Washington, DC: Author.

Vincent, B. S., \& Hofer, P. J. (1994). The consequences of mandatory minimum prison terms: A summary of recent findings. Washington, DC: Federal Judicial Center.

Walker, S. (1993). Taming the system: The control of discretion in criminal justice, 1950-1990. New York: Oxford University Press. 
Wheeler, S., Mann, K., \& Sarat, A. (1988). Sitting in judgement: The sentencing of white-collar criminals. New Haven, CT: Yale University Press.

Wilmot, K. A., \& Spohn, C. (2004). Prosecutorial discretion and real-offense sentencing: An analysis of relevant conduct under the federal sentencing guidelines. Criminal Justice Policy Review, 15(3), 324-343.

Worrall, J. L. (2004). Effect of three-strikes legislation on serious crime in California. Journal of Criminal Justice, 32(4), 283-296.

Wray, H. R. (1993). Mandatory minimum sentences: Are they being imposed and who is receiving them? Washington, DC: General Accounting Office.

Zatz, M. S., \& Hagan, J. (1985). Crime, time, and punishment: An exploration of selection bias in sentencing research. Journal of Quantitative Criminology, 1(1), 103-126.

Paula M. Kautt is a lecturer of applied criminology at the University of Cambridge, Institute of Criminology. She is currently engaged in a nationwide project funded by the Home Office to evaluate sentencing outcomes in England and Wales. In 2000, she earned a doctorate in criminal justice but also has practitioner experience in the Kansas Department of Corrections. Her research interests include criminal courts and sentencing, advanced quantitative methods, policing, as well as hate crime statute implementation and enforcement. These also include a wide variety of correctional topics including the validity of offender assessment tools, comparison of paroleeligible and "flat-time" inmates, as well as correctional staff motivation. Her research has been published by Justice Quarterly, The Federal Sentencing Reporter, and the National Institute of Justice. She has also received research grants from the American Statistical Society and the National Institute of Justice.

Miriam A. Delone is an associate professor in the Department of Criminal Justice at the University of Nebraska. Her research interests include race, ethnicity and sentencing; political economy and social control; and the formation and impact of moral panics on crime control policy. She is coauthor of the book, The Color of Justice and former editor of The Criminologist. 